\title{
An Evaluation of Pharmacological Management of Pemphigus Vulgaris and its Impact on Quality of Life
}

\author{
Panchal Kiran M${ }^{1}$, Gandhi Anuradha $\mathrm{M}^{2 *}$, Patel Prakruti $\mathrm{P}^{3}$, Sutaria Amita ${ }^{4}$, Desai Mira K ${ }^{5}$ \\ ${ }^{1}$ Third Year Resident of Pharmacology, B. J. Medical College and Civil Hospital, Ahmedabad, Gujarat, INDIA. \\ ${ }^{2}$ Additional Professor of Pharmacology, B. J. Medical College and Civil Hospital, Ahmedabad, Gujarat, INDIA. \\ ${ }^{3}$ Associate Professor of Pharmacology, B. J. Medical College and Civil Hospital, Ahmedabad, Gujarat, INDIA. \\ ${ }^{4}$ Assistant Professor, Department of Skin and Venereology, B. J. Medical College and Civil Hospital, Ahmedabad, Gujarat, INDIA \\ ${ }^{5}$ Professor and Head of Department of Pharmacology, B. J. Medical College and Civil Hospital, Ahmedabad, Gujarat, INDIA
}

\begin{abstract}
Objectives: To study use, effect and adverse drug reaction (ADR) of the drugs and its impact on quality of life in patients suffering from Pemphigus vulgaris (PV). Materials and Methods: Prospective, observational study was carried out in newly diagnosed patients of PV. Baseline and follow-up data at 2, 6 and 12 weeks; disease severity (Kumar's score), Quality of Life [Dermatology Life Quality Index (DLQI)] and ADR were recorded. Data analyzed by one-way and repeated measure ANOVA test. Results: Total 84 patients were included [Group A: Corticosteroid $(n=29)$, Group B: Corticosteroid + Azathioprine $(n=30)$, Group C: Corticosteroid + rituximab $(n=25)]$. Significant reduction $(P<0.001)$ observed in Kumar's and DLQ score at $2^{\text {nd }}$ and $3^{\text {rd }}$ follow-up as compared to baseline and $1^{\text {st }}$ follow up and at $3^{\text {rd }}$ follow-up as compared $2^{\text {nd }}$ follow-up in group A, B and C. Mean difference between baseline and $3^{\text {rd }}$ follow up of Kumar's score and DLQI was significantly higher in group $C$ as compared to group $A$ ( $p<0.01$ and $p<0.001$, respectively) and $B(p<0.05$ and $p<0.05$, respectively). Correlation between Kumar's and DLQI score was significant in group $C(P<0.05)$.
\end{abstract}

ADRs were reported in group A $(68.96 \%), B(63.33 \%)$ and C $(52 \%)$. Cost of rituximab was significantly $(p<0.001)$ higher. Conclusion: Corticosteroid with rituximab is associated with better efficacy and improvement in QOL but more expensive than corticosteroid alone / in combination with azathioprine for the treatment of Pemphigus vulgaris.

Key words: Pemphigus vulgaris, Kumar's score, Dermatology life Quality Index, Corticosteroid, Rituximab.

Correspondence

Dr. Anuradha Gandhi, Additional Professor, Department of Pharmacology B. J. Medical College, Ahmedabad - 380016, Gujarat, INDIA.

Phone: +919904903110

Email: dr_anuradha1@yahoo.co.in

DOI: 10.5530/jyp.2018.10.95

\section{INTRODUCTION}

Pemphigus vulgaris is a rare autoimmune blistering disease of skin and mucous membranes. The Worldwide incidence of Pemphigus vulgaris is 0.5 to 3.2 cases per one lakh populations/year. ${ }^{1}$ In India, incidence of Pemphigus vulgaris is 4.4 cases per million populations/year. ${ }^{2}$ Patients of Pemphigus vulgaris are presented with flaccid, thin walled vesicles and/ or bullae which are commonly rupture to leave an area of erosion and ulceration. Involvement of various mucosal surfaces such as oral, ocular, nasal, pharyngeal, laryngeal, upper respiratory and anogenital mucous membrane is present in Pemphigus vulgaris. Majority of patients with Pemphigus vulgaris develop painful erosions of the oral and skin lesion due to involvement of peripheral nerves. ${ }^{3}$

The choice of therapy depends on severity of the disease, efficacy, safety, availability and cost of drugs. ${ }^{4}$ Corticosteroid are preferred therapy for Pemphigus vulgaris, azathioprine is used for its corticosteroid-sparing effect and it is first line adjuvant immunosuppressant agent. ${ }^{5}$ Rituximab, an anti-CD20 monoclonal antibody is indicated for moderate to severe refractory cases, contraindication or severe ADR to systemic corticosteroids and immunosupressants. ${ }^{6}$ High-dose Intravenous immunoglobulin G (IVIG) and plasmapheresis can also be indicated in resistant cases. ${ }^{5}$ Disease symptoms e.g. painful lesions, disease severity and complications due to treatment e.g. ADR may adversely affect the quality of life of patients. ${ }^{7}$ Therefore, quality of life measures can be used to guide and evaluate treatment interventions.
During extensive literature search, we observed studies reported from different countries about efficacy (i.e. Pemphigus area and activity score, Pemphigus disease area index), evaluation of quality of life (i.e. skindex-29, short form-36, autoimmune Bullous Disease Quality of Life Questionnaire) and correlation of efficacy and QOL in patients of Pemphigus vulgaris. ${ }^{8-10}$ We did not find any Indian study showing efficacy and correlation of efficacy with QOL over a period of time. Hence, this study was carried out to study the use and effect of the drugs as well as its impact on quality of life in patient suffering from Pemphigus vulgaris.

\section{MATERIALS AND METHODS}

Permissions to conduct the study were obtained from the Institutional Ethics committee (IEC No -208/15) and the Head of Department of Dermatology and Venereology. All newly diagnosed patients of Pemphigus vulgaris by Dermatologist, between 18 to 65 years of either gender, who are willing to participate in the study and gave written informed consent were enrolled. Patients who were suffering from severe or uncontrolled cases of hypertension, diabetes mellitus, hepatic, renal, pulmonary, hematologic disorders and pregnant as well as lactating women were excluded. This was an observational, prospective, single center study carried out at department of skin and venereal disease of a tertiary care teaching hospital over a period of 24 months from November 2015 to November 2017. The baseline data like demographic details, clinical history, details of laboratory investigation, disease of severity (Kumar's

This is an open access article distributed under the terms of the Creative Commons Attribution-NonCommercial-ShareAlike 4.0 License, which allows others to remix, tweak, and build upon the work non-commercially, as long as the author is credited and the new creations are licensed under the identical terms. 
score), Quality of Life (DLQI) and details of the drug treatment were recorded in predefined Case Record Form (CRF).

Based on prescribed treatment by dermatologist, patients were Grouped as: Group A ( $\mathrm{n}=29)$ : \{corticosteroid group [inj. dexamethasone 4 to $6 \mathrm{mg}$ once a day intravenously followed by tab prednisolone 20 to $40 \mathrm{mg}$ once a day and maintained by 10 to $20 \mathrm{mg}$ of prednisolone once a day] $\}$, Group B $(\mathrm{n}=30)$ : \{corticosteroid [inj. dexamethasone 4 to $6 \mathrm{mg}$ once a day intravenously followed by tab prednisolone 20 to $40 \mathrm{mg}$ once a day and maintained by 10 to $20 \mathrm{mg}$ of prednisolone once a day] plus azathioprine [ $50 \mathrm{mg}$ twice daily] group and Group $\mathrm{C}(\mathrm{n}=25)$ : \{corticosteroid [inj. dexamethasone 4 to $6 \mathrm{mg}$ once a day intravenously followed by tab prednisolone $20 \mathrm{mg}$ once a day and maintained by 5 to $20 \mathrm{mg}$ of prednisolone once a day] plus rituximab [ 1 gm Injection 2 times at 15 days interval (Total 2 injections)]\}. All study treatments were allocated to patients by government supply and treatment selection was based on decision of dermatologist. All patients were followed at 2 ( $1^{\text {st }}$ follow up), 6 ( $2^{\text {nd }}$ follow-up) and 12 weeks ( $3^{\text {rd }}$ follow up). Disease severity was assessed by Kumar's score ${ }^{11}$ and Quality of Life was assessed by Dermatology Life Quality Index (DLQI). ${ }^{12}$ At each follow up visit, presenting complaints, any change in drug treatment, Kumar's score and quality of life was recorded and analyzed at the end of the study. Details of the adverse drug reaction (ADR) if any, was recorded in the CRF. Analysis of cost of drug incurred was calculated for given treatment from time of enrollment to $3^{\text {rd }}$ follow up visit.

The data was recorded in Microsoft Excel Worksheet version 2013. The statistical evaluation was done using Analysis of Variance (ANOVA) test with the help of Graph Pad demo version 3.1. Intra-group comparison was done between baseline and at each follow up visits by repeated measure ANOVA test. Intergroup comparison was done between group A, $\mathrm{B}$ and group $\mathrm{C}$ by one way ANOVA test. $p<0.05$ was considered to be statistically significant.

\section{RESULTS}

Total 84 patients were included in the study according to inclusion and exclusion criteria. Patients were followed up at the 2 weeks ( $1^{\text {st }}$ follow up), 6 weeks ( $2^{\text {nd }}$ follow up) and 12 weeks ( $3^{\text {rd }}$ follow up) of treatment.

As shown in Table 1, the mean age of total number of patients was $45.42 \pm 1.58$ years, $33(39.28 \%)$ male and $51(60.72 \%)$ were female patients with higher female to male ratio. (Table 1)

Mean of baseline Kumar's score was comparable between all groups $[4.31 \pm 0.14$ (group A), $4.70 \pm 0.13$ (group B) and $4.68 \pm 0.22$ (group $\mathrm{C})$ ]. There was significant reduction $(\mathrm{p}<0.001)$ in oral and skin score and total Kumar's score and at $2^{\text {nd }}$ and $3^{\text {rd }}$ follow-up as compared to baseline and $1^{\text {st }}$ follow up and at $3^{\text {rd }}$ follow up as compared to $2^{\text {nd }}$ follow up in all treatment groups. At $3^{\text {rd }}$ follow up, there was significant $(p<0.01)$ reduction in Kumar's score in group C as compared to group A and group B. (Figure 1) Mean difference of Kumar's score between baseline and $3^{\text {rd }}$ follow up data was significantly higher in group $\mathrm{C}$ as compared to group A $(p<0.01)$ and group B $(p<0.05)$. (Table 2) Total 3 patients $(10.34 \%)$ in group A, 4 patients (13.33\%) in group B and 12 patients (48\%) in group $\mathrm{C}$ achieved complete reduction in Kumar's score at $3^{\text {rd }}$ follow up (12 weeks). (Table 3 )

\section{Quality of life}

Mean baseline DLQI score was comparable between all groups [13.75 \pm 0.30 (group A), $13.76 \pm 0.38$ (group B) and $14.08 \pm 0.42$ (group C)] Total DLQI score was significantly $(p<0.001)$ reduced at $2^{\text {nd }}$ and $3^{\text {rd }}$ follow up as compared to baseline and $1^{\text {st }}$ follow up and also at $3^{\text {rd }}$ follow up as compared to $2^{\text {nd }}$ follow up in group A, B and C. At $3^{\text {rd }}$ follow up, there was significant $(p<0.01)$ reduction in DLQI score in group $\mathrm{C}$ as compared to group A and group B. (Figure 2)
Table 1: Comparison of demographics characteristics and presenting symptoms of patients suffering from PV ( $n=84)$.

\begin{tabular}{|c|c|c|c|}
\hline Parameter & $\begin{array}{c}\text { Group A } \\
\text { Corticosteroid } \\
(n=29)\end{array}$ & $\begin{array}{c}\text { Group B } \\
\text { Corticosteroid } \\
+ \\
\text { Azathioprine } \\
\quad(n=30)\end{array}$ & $\begin{array}{c}\text { Group C } \\
\text { Corticosteroid } \\
+ \text { Rituximab } \\
\quad(n=25)\end{array}$ \\
\hline $\begin{array}{c}\text { Age (year) } \\
(\text { Mean } \pm \text { SEM })\end{array}$ & $47.34 \pm 2.78$ & $45.60 \pm 2.58$ & $43.00 \pm 2.92$ \\
\hline $\begin{array}{c}\text { Gender } \\
\text { (M:F ratio) }\end{array}$ & $\begin{array}{c}\text { M:11 F : } 18 \\
(1: 1.63)\end{array}$ & $\begin{array}{c}\mathrm{M}: 13 \quad \mathrm{~F}: 17 \\
(1: 1.30)\end{array}$ & $\begin{array}{c}\text { M:09 F :16 } \\
(1: 1.77)\end{array}$ \\
\hline $\begin{array}{l}\text { Weight }(\mathbf{k g}) \\
(\text { Mean } \pm \text { SEM })\end{array}$ & $56.34 \pm 2.59$ & $58.26 \pm 2.75$ & $59.68 \pm 3.12$ \\
\hline \multicolumn{4}{|c|}{ Level of education } \\
\hline Illiterate & $12(41.37 \%)$ & $8(26.66 \%)$ & $4(16 \%)$ \\
\hline Up to $12^{\text {th }}$ & $16(55.17 \%)$ & $19(63.33 \%)$ & $20(80 \%)$ \\
\hline Graduate & $01(3.44 \%)$ & $03(10 \%)$ & $01(4 \%)$ \\
\hline \multicolumn{4}{|c|}{ Presenting symptoms of patients } \\
\hline Fluid filled lesions & $28(96.55 \%)$ & $29(96.66 \%)$ & $25(100 \%)$ \\
\hline Painful oral lesions & $26(89.65 \%)$ & $27(90.00 \%)$ & $23(92.00 \%)$ \\
\hline Limiting food intake & $20(68.96 \%)$ & $23(76.66 \%)$ & $19(76.00 \%)$ \\
\hline $\begin{array}{l}\text { Painful lesion over } \\
\text { body }\end{array}$ & $19(65.51 \%)$ & $22(73.33 \%)$ & $18(72.00 \%)$ \\
\hline $\begin{array}{c}\text { Erosion or crusting } \\
\text { over lesions }\end{array}$ & $17(58.62 \%)$ & $19(63.33 \%)$ & $15(60.00 \%)$ \\
\hline
\end{tabular}

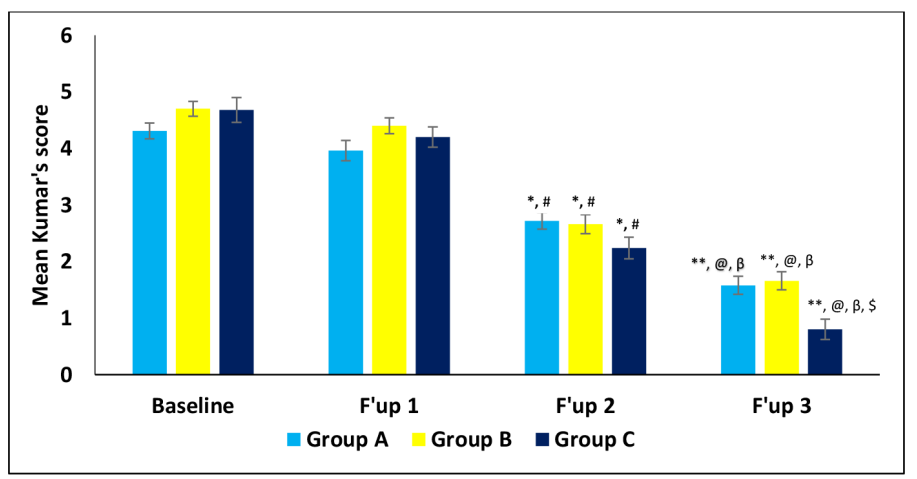

Figure 1: Comparison of efficacy (Kumar's score) between corticosteroid (group A), corticosteroid + azathioprine (group B) and corticosteroid + rituximab (group $C$ ) in patients suffering from pemphigus vulgaris $(n=84)$.

Intragroup comparison was done by repeated measure ANOVA test followed by post hoc analysis using Tukey-Kramer multiple comparison test. Intergroup comparison was done by primary ordinary ANOVA test followed by post hoc analysis using Tukey-Kramer multiple comparison test. " $p<0.001$ at $2^{\text {nd }}$ follow up as compared to baseline ${ }^{*} p<0.001$ at $2^{\text {nd }}$ follow up as compared to $1^{\text {st }}$ follow up ${ }^{* *} p<0.001$ at $3^{\text {rd }}$ follow up as compared to baseline ${ }^{\circledR} p<0.001$ at $3^{\text {rd }}$ follow up as compared to $1^{\text {st }}$ follow up ${ }^{\beta} p<0.001$ at $3^{\text {rd }}$ follow up as compared to $2^{\text {nd }}$ follow up $\$ p<0.01$ in group $C$ as compared to group $A$ and $B$ 
Kiran, et al.: Evaluation of Pharmacological Management of Pemphigus Vulgaris and its Impact on Quality of Life.

Table 2: Comparison of Kumar's score, DLQI score and each parameter of DLQI score in corticosteroid (group A), corticosteroid + azathioprine (group B) and corticosteroid + rituximab (group C) (Mean \pm SEM) $(n=84)$.

\begin{tabular}{|c|c|c|c|}
\hline $\begin{array}{l}\text { Score (Mean } \\
\text { difference between } \\
\text { baseline and } 3^{\text {rd }} \\
\text { follow up) }\end{array}$ & $\begin{array}{c}\text { Group A } \\
\text { Corticosteroid } \\
(n=29)\end{array}$ & $\begin{array}{c}\text { Group B } \\
\text { Corticosteroid } \\
+ \\
\text { Azathioprine } \\
\quad(n=30)\end{array}$ & $\begin{array}{c}\text { Group C } \\
\text { Corticosteroid + } \\
\text { Rituximab } \\
(n=25)\end{array}$ \\
\hline \multicolumn{4}{|c|}{ Kumar's Score } \\
\hline Oral site score & $1.17 \pm 0.10$ & $1.43 \pm 0.11$ & $1.64 \pm 0.16^{*}$ \\
\hline Skin site score & $1.55 \pm 0.19$ & $1.53 \pm 0.10$ & $2.24 \pm 0.14^{* *, \#}$ \\
\hline Kumar's total Score & $2.72 \pm 0.24$ & $3.03 \pm 0.16$ & $3.88 \pm 0.25^{* *, @ ~}$ \\
\hline \multicolumn{4}{|c|}{ DLQI Score } \\
\hline Symptoms and feeling & $1.79 \pm 0.14$ & $2.03 \pm 0.13$ & $2.4 \pm 0.12^{* *}$ \\
\hline Daily activities & $1.68 \pm 0.16$ & $1.7 \pm 0.16$ & $1.92 \pm 0.16$ \\
\hline Leisure & $0.93 \pm 0.12$ & $1.2 \pm 0.16$ & $1.08 \pm 0.17$ \\
\hline Work or school & $0.65 \pm 0.10$ & $0.8 \pm 0.11$ & $0.88 \pm 0.14$ \\
\hline Personal relationship & $0.65 \pm 0.12$ & $0.5 \pm 0.10$ & $0.60 \pm 0.11$ \\
\hline Treatment & $0.62 \pm 0.11$ & $0.56 \pm 0.10$ & $0.92 \pm 0.09$ \\
\hline DLQI total Score & $6.34 \pm 0.28$ & $6.80 \pm 0.28$ & $7.80 \pm 0.20^{* *}, @$ \\
\hline
\end{tabular}

Intergroup comparison was done by primary ordinary ANOVA test followed by post hoc analysis using Tukey-Kramer multiple comparison test.

${ }^{*} p<0.05$ in group $\mathrm{C}$ as compared to group $\mathrm{A}$

${ }^{* *} p<0.01$ in group $\mathrm{C}$ as compared to group $\mathrm{A}$

${ }^{*} p<0.01$ in group $\mathrm{C}$ as compared to group $\mathrm{B}$

${ }^{\circledR} p<0.05$ in group $\mathrm{C}$ as compared to group $\mathrm{B}$

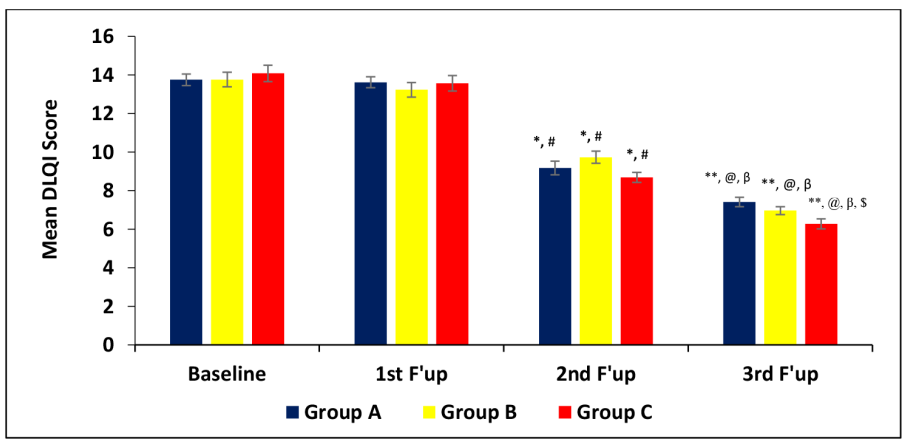

Figure 2: Comparison of Quality of Life (DLQI) between corticosteroid (group A), corticosteroid + azathioprine (group B) and corticosteroid + rituximab (group $C$ ) in patients suffering from pemphigus vulgaris $(n=84)$

Intragroup comparison was done by repeated measure ANOVA test followed by post hoc analysis using Tukey-Kramer multiple comparison test. Intergroup comparison was done by primary ordinary ANOVA test followed by post hoc analysis using Tukey-Kramer multiple comparison test.

${ }^{*} p<0.001$ at $2^{\text {nd }}$ follow up as compared to baseline

$\# p<0.001$ at $2^{\text {nd }}$ follow up as compared to $1^{\text {st }}$ follow up

${ }^{* *} p<0.001$ at $3^{\text {rd }}$ follow up as compared to baseline

$@ p<0.001$ at $3^{\text {rd }}$ follow up as compared to $1^{\text {st }}$ follow up

${ }^{\beta} p<0.001$ at $3^{\text {rd }}$ follow up as compared to $2^{\text {nd }}$ follow up

${ }^{\$} p<0.01$ in group $C$ as compared to group $A$ and $B$
Table 3: Analysis of complete remission, cost of drug incurred and adverse drug reactions (ADR) in patients suffering from pemphigus vulgaris $(\mathbf{n}=\mathbf{8 4})$.

\begin{tabular}{|c|c|c|c|c|}
\hline $\begin{array}{l}\text { Sr. } \\
\text { no }\end{array}$ & Parameters & $\begin{array}{c}\text { Group A } \\
(n=29)\end{array}$ & $\begin{array}{c}\text { Group B } \\
(n=30)\end{array}$ & $\begin{array}{c}\text { Group C } \\
(n=25)\end{array}$ \\
\hline 1 & $\begin{array}{l}\text { Complete } \\
\text { remission }\end{array}$ & $10 \%$ & $13 \%$ & $48 \%$ \\
\hline 2 & $\begin{array}{l}\text { Cost of drug } \\
\text { incurred }\end{array}$ & 1787.66 ₹ & $2620.84 ₹$ & $51,371.40 ₹$ \\
\hline \multirow[t]{23}{*}{3} & $\begin{array}{c}\text { Adverse drug } \\
\text { reactions (Total) }\end{array}$ & $20(68.96 \%)$ & $19(63.33 \%)$ & $13(52 \%)$ \\
\hline & Oral candidiasis & $2(7 \%)$ & $2(6.66 \%)$ & $2(8 \%)$ \\
\hline & Pedal edema & $3(10.34 \%)$ & $2(6.66 \%)$ & $1(4 \%)$ \\
\hline & Fever & $3(10.34 \%)$ & $1(3.33 \%)$ & $1(4 \%)$ \\
\hline & Acne & $3(10.34 \%)$ & $2(6.66 \%)$ & $1(4 \%)$ \\
\hline & Weight gain & $2(7 \%)$ & $2(6.66 \%)$ & - \\
\hline & Pneumonia & $1(3.44 \%)$ & - & $1(4 \%)$ \\
\hline & Infection & $1(3.44 \%)$ & $1(3.33 \%)$ & - \\
\hline & $\begin{array}{l}\text { Urinary tract } \\
\text { infection }\end{array}$ & $2(7 \%)$ & $1(3.33 \%)$ & - \\
\hline & Hyperglycaemia & $1(3.44 \%)$ & $1(3.33 \%)$ & - \\
\hline & Diabetes mellitus & $1(3.44 \%)$ & - & - \\
\hline & Hypertension & $1(3.44 \%)$ & $1(3.33 \%)$ & - \\
\hline & Abdominal pain & - & $1(3.33 \%)$ & - \\
\hline & Diarrhoea & - & $2(6.66 \%)$ & - \\
\hline & Vomiting & - & $2(6.66 \%)$ & - \\
\hline & $\begin{array}{l}\text { Pseudomonas } \\
\text { infection }\end{array}$ & - & $1(3.33 \%)$ & - \\
\hline & Headache & - & - & $1(4 \%)$ \\
\hline & Dizziness & - & - & $1(4 \%)$ \\
\hline & Flushing & - & - & $1(4 \%)$ \\
\hline & Pneumonia & - & - & $1(4 \%)$ \\
\hline & $\begin{array}{l}\text { Hepatic function } \\
\text { abnormal }\end{array}$ & - & - & $1(4 \%)$ \\
\hline & Chills and rigor & - & - & $2(8 \%)$ \\
\hline & Hoarseness of voice & - & - & $1(4 \%)$ \\
\hline
\end{tabular}

\section{QOL at $2^{\text {nd }}$ follow up:}

In group $\mathrm{A}$, each parameter of QOL (except treatment parameter) was significantly $(p<0.001)$ reduced at $2^{\text {nd }}$ follow up as compared to baseline and $1^{\text {st }}$ follow up. Treatment parameter was significantly $(\mathrm{p}<0.01)$ reduced at $2^{\text {nd }}$ follow up as compared to baseline. In group B, symptoms and feelings, daily activities, leisure and work or school parameter of QOL was significantly $(p<0.001)$ reduced at $2^{\text {nd }}$ follow up as compared to baseline and $1^{\text {st }}$ follow up while treatment parameter was significantly $(\mathrm{p}<0.05)$ reduced at $2^{\text {nd }}$ follow up as compared to $1^{\text {st }}$ follow up ( 2 weeks). In group C, each parameter of QOL was significantly $(p<0.001)$ reduced at $2^{\text {nd }}$ follow up as compared to baseline. Symptoms and feeling, daily activities, leisure, personal relationship and treatment parameter was significantly $(p<0.001)$ reduced at $2^{\text {nd }}$ follow up as compared to $1^{\text {st }}$ follow up while work and school parameter was significantly $(p<0.01)$ reduced at $2^{\text {nd }}$ follow up as compared to $1^{\text {st }}$ follow up in group C. 


\section{QOL at $3^{\text {rd }}$ follow up:}

Mean score of each parameter of QOL significantly $(p<0.001)$ reduced at $3^{\text {rd }}$ follow up as compared to baseline and $1^{\text {st }}$ follow up in all treatment group. Significant $(p<0.001)$ reduction in symptoms and feeling parameter of QOL at $3^{\text {rd }}$ follow up as compared to $2^{\text {nd }}$ follow up and significant $(p<0.01)$ reduction in work and school parameter of QOL at $3^{\text {rd }}$ follow up as compared to $2^{\text {nd }}$ follow up was seen in group A. In group B, significant $(p<0.001)$ reduction in symptoms and feeling, work and school and personal relationship parameter of QOL at $3^{\text {rd }}$ follow up as compared to $2^{\text {nd }}$ follow up and significant $(p<0.01)$ reduction in daily activities and treatment parameter of QOL at $3^{\text {rd }}$ follow up as compared to $2^{\text {nd }}$ follow up was observed. In group C, significant $(p<0.001)$ reduction was seen in symptoms and feeling and treatment parameter of QOL at $3^{\text {rd }}$ follow up as compared to $2^{\text {nd }}$ follow up and also significant $(p<0.05)$ reduction in work and school parameter of QOL at $3^{\text {rd }}$ follow up as compared to $2^{\text {nd }}$ follow up.

Mean difference of DLQI score was significantly higher in group $\mathrm{C}$ as compared to group A $(p<0.001)$ and group B $(p<0.05)$. Mean difference of symptoms and feelings parameter at $3^{\text {rd }}$ follow up was significantly higher in group $\mathrm{C}$ as compared to group $\mathrm{A}(p<0.01)$. (Table 2)

\section{Correlation between Kumar's Score and Quality of Life}

Correlation between Kumar's score and QOL was carried out using Pearson parametric correlation test. Weak positive correlation in group A $(0.39)$ and $\mathrm{B}(0.49)$ and strong positive correlation in group $\mathrm{C}(0.58)$ was observed. (Figure 3) Significant correlation was seen in group $C(p<0.05)$.

\section{Adverse drug reaction}

Out of 52 adverse drug reaction, 20 (38.46\%), 19 (36.53\%) and 13 (25\%) ADRs were reported in in group A, B and C respectively. All ADRs were reported to regional $\mathrm{ADR}$ monitoring center of Pharmacovigilance Programme of India (PvPI). All ADRs were assessed as possible except weight gain, infection and vomiting which were assessed as probable by using WHO-UMC causality assessment score. All ADRs were assesses as not preventable by using modified Schumock and Thornton scale. $(\text { Table } 3)^{13}$

Mean cost of drug incurred per patient was $1787.66 \neq, 2620.84 \neq$ and $51,371.40 \neq$ in group $\mathrm{A}, \mathrm{B}$ and $\mathrm{C}$ respectively. It was observed that the total and individual cost of drug incurred was significantly $(p<0.001)$ higher in group $\mathrm{C}$ as compared to group A and B. (Table 3)

\section{DISCUSSION}

In the present study, efficacy of drugs and QOL in newly diagnosed patients suffering from Pemphigus vulgaris were studied.

In our study, we observed higher number of female patients suffering from Pemphigus vulgaris (60.72\%). Corticosteroid alone/in combination with azathioprine/or in combination with rituximab significantly $(p<0.001)$ reduced disease severity (Kumar's score) and improve QOL (DLQI) at $2^{\text {nd }}$ (6 weeks) and $3^{\text {rd }}$ follow-up (12 weeks) as compared to baseline and $1^{\text {st }}$ follow-up ( 2 weeks). We observed that nearly half of the patients in group $\mathrm{C}$ achieved complete remission (complete reduction in Kumar's score) at $3^{\text {rd }}$ follow-up (12 weeks) which was higher as compared to group A (10\%) and group B (13\%). Patients treated with corticosteroid plus rituximab therapy developed less ADRs (25\%) than corticosteroid alone (38.46\%) and corticosteroid with azathioprine treated group (36.53\%).

In our study, $60.72 \%$ were female patients followed by labourers $(22.61 \%)$ and farmers (15.47\%). Estrogen (increases immunity, autoantibody production $)^{14}$ may be contributing factor for higher number of female patients (particularly housewives) in our study. ${ }^{15}$ Sun exposure can worsen

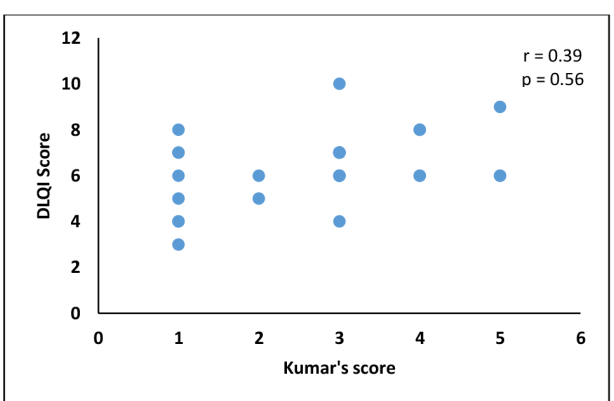

Group A $(\mathrm{n}=29)$

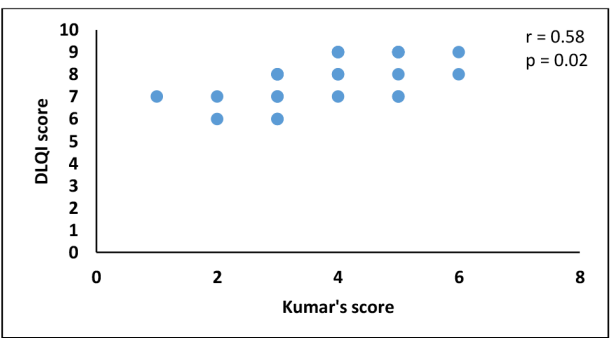

roup B ( $\mathrm{n}=30)$

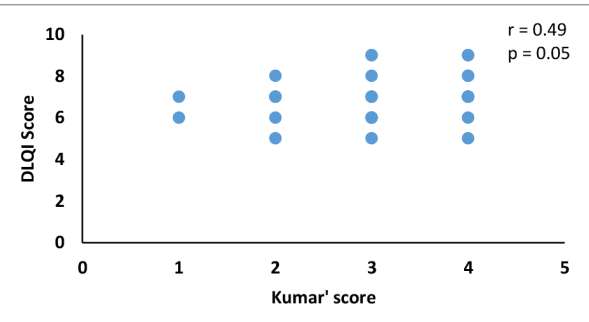

Group $\mathrm{C}(\mathrm{n}=25)$

Figure 3: Correlation between Kumar's score and DLQI score in corticosteroid (group A), corticosteroid + azathioprine (group B) and corticosteroid + rituximab (group $C)(n=84)$.

the Pemphigus vulgaris particularly in patients who are working in open space e.g. farmers, labourers. ${ }^{16}$

Our study shows corticosteroid alone or in combination with azathioprine or rituximab significantly $(p<0.001)$ decrease severity of disease by reducing both oral and skin site of Kumar's score at $2^{\text {nd }}$ and $3^{\text {rd }}$ follow-up i.e. 6 and 12 weeks respectively. Similar results were observed in different studies with corticosteroid alone ${ }^{17}$ corticosteroid plus azathioprine ${ }^{18}$ and corticosteroid plus rituximab ${ }^{19}$ treatment in Pemphigus vulgaris. Corticosteroid decreases inflammation by suppressive effects on cytokines and other mediators of inflammation. ${ }^{20}$ In addition, azathioprine plus corticosteroid combination decreases the proliferation by inhibiting synthesis of purines and impaired the lymphocyte function after 4-8 weeks. ${ }^{21}$ Rituximab decreases the precursor of autoantibody producing plasma cells and marked decrease in anti-desmoglein-3 antibodies within 4-6 weeks. ${ }^{22}$ Thus disease severity is reduced by corticosteroid alone or in combination with azathioprine or rituximab.

At the end of 12 weeks, we observed that, there was significant $(p<0.01)$ reduction in both oral and skin site Kumar's score in group $\mathrm{C}$ as compared to group A and group B. Mean difference (Baseline to $3^{\text {rd }}$ follow up) of Kumar's score was also significantly higher in group $C$ as compared to group A $(p<0.01)$ and group B $(p<0.05)$. This suggest better efficacy of corticosteroid plus rituximab therapy as compared to corticosteroid alone and corticosteroid plus azathioprine therapy.

In our study, nearly half of the patients in group $\mathrm{C}$ achieved complete remission of disease at $3^{\text {rd }}$ follow-up which was higher as compared to group A (10\%) and group B (13\%). Kanwar study (2012) reported 40\% complete remission where rituximab $375 \mathrm{mg} / \mathrm{m}^{2}$ was given once weekly 
Kiran, et al.: Evaluation of Pharmacological Management of Pemphigus Vulgaris and its Impact on Quality of Life.

for 4 weeks. ${ }^{23}$ In our study, 1 gm of rituximab dose was prescribed for 2 times at 15 days interval. This could be the contributing factor for higher rate of complete remission in our study.

Corticosteroid alone, corticosteroid plus azathioprine and corticosteroid plus rituximab therapy improves QOL by reducing score of each parameter and total DLQI score after 6 and 12 weeks of treatment. This suggests reduction in disease severity over a period of 12 weeks and hence patients feel better, taking interest in daily activities, able to participate in social activities (including improvement in relation with family members and friends) and improvement in work output at working place. At the end of 12 weeks, we observed that, there was significant $(p<0.01)$ reduction in DLQI score in group C as compared to group A and group B. Mean difference (Baseline to $3^{\text {rd }}$ follow up) of DLQI score was significantly higher in group $\mathrm{C}$ as compared to group A $(p<0.001)$ and group B $(p<0.05)$. Analysis of each parameter of QOL between treatment groups suggest that there was significant improvement in symptoms and feeling parameters in corticosteroid plus rituximab group than corticosteroid alone patients. Intergroup comparison suggest that there was significant improvement in QOL in patients treated with corticosteroid plus rituximab therapy as compared to corticosteroid alone and corticosteroid plus azathioprine therapy.

Positive correlation between Kumar's score and DLQI score was seen in all groups which suggest that when Kumar's score decreases (decrease in disease severity), the DLQI score also decreases (improvement in QOL). All groups were associated with positive correlation between efficacy and QOL indicating decrease in disease severity associated with improvement in QOL. The correlation between Kumar's score and QOL was significant in treatment group $\mathrm{C}(p<0.05)$ as compared to group A and B which suggests patients treated with corticosteroid plus rituximab lead to more improvement in QOL than corticosteroid alone and corticosteroid plus azathioprine therapy. Complete remission in disease severity in corticosteroid plus rituximab group can lead to better correlation between efficacy and QOL.

Decrease in inflammation and inflammatory cytokines (corticosteroid), inhibition of synthesis of purines, impairment in lymphocyte function (corticosteroid plus azathioprine), reduction in autoantibodies (dsg-1 and -3 ) and depletion of B cell (corticosteroid plus rituximab) can lead to decrease in disease severity and hence improve QOL. In corticosteroid plus rituximab group, better reduction in disease severity and improvement in QOL was observed as compared to corticosteroid alone/plus azathioprine group (prednisolone- 10-20 mg). In addition, maintenance dose of prednisolone requirement is less $(5-10 \mathrm{mg})$ in corticosteroid plus rituximab group which may contribute to less ADR particularly ADR due to corticosteroid. In our study, patients developed pedal edema, fever, acne, oral candidiasis, urinary tract infection, weight gain, hyperglycemia, infection, pneumonia, diabetes mellitus and hypertension who administered dexamethasone or prednisolone. In a study carried out by Lihite et al., (2016) it was reported that the patient treated with corticosteroid therapy also developed ADRs such as oral candidiasis, pulmonary edema, hyperglycemia, secondary infections, electrolytes imbalance, gastritis, lung abscess, psychosis, and septicaemia. ${ }^{24}$ Major disadvantage with rituximab is higher cost as rituximab is too expensive.

\section{CONCLUSION}

Our study concludes, all treatment groups are efficacious for the treatment of Pemphigus vulgaris. Corticosteroid alone and corticosteroid plus azathioprine having similar efficacy for treatment and improvement of the QOL in patients suffering from pemphigus vulgaris. Corticosteroid plus rituximab combination therapy is more efficacious, can cause complete remission and associated with significant improvement of QOL with less ADRs but too expensive than corticosteroid alone or in combination with azathioprine therapy. We have evaluated efficacy and QOL over a period of time and done correlation between efficacy and QOL. Due to chronic nature of disease, longer study duration with large sample size will help to better analysis of correlation between efficacy and QOL.

\section{ACKNOWLEDGEMENT}

I am extremely thankful to Dr. Bela J. Shah, Head of Department of Skin and Venereal Diseases, Civil Hospital Ahmedabad for granting me the permission to conduct the study in Department of Skin and Venereal Diseases. Also thankful to all the patients of Pemphigus vulgaris for their co-operation during study without whom it was impossible to do this research work.

\section{CONFLICT OF INTEREST}

The authors declare no conflict of interest.

\section{ABBREVIATIONS}

ADR: Adverse drug reaction; ANOVA: Analysis of variance; CRF: Case record form; DLQI: Dermatology life quality index; IvIG: Immunoglobulin G; PV: Pemphigus vulgaris; PvPI: Pharmacovigilance progamme of india; QoL: Quality of life.

\section{REFERENCES}

1. Ganapathy S, Vedam V, Rajeev V, Arunachalam R. Autoimmune Disorder-immunopathogenesis and Potential Therapies. J Young Pharma. 2017;9(1):14-22.

2. Javidi Z, Meibodi NT, Nahidi Y. Epidemiology of pemphigus in northeast Iran: A 10-year Retrospective study. Indian J Dermatol. 2007;52:188-91.

3. Darling MR, DaleyT. Blistering mucocutaneous diseases of the oral mucosa-a review: part 2. Pemphigus vulgaris. J Can Dent Assoc. 2006;72(1):63-6.

4. Kanwar AJ, Vinay K. Treatment of pemphigus: An Indian perspective. Indian J Dermatol Venereol Leprol. 2014;80(4):285-8

5. Masayuki A, Pemphigus. In: Bolognia JL, Jorrizo JL, Schaffer JV, editors. Textbook of Dermatology. $3^{\text {rd }}$ edition. China. Elsevier Ltd. 2012.p.461-5.

6. Ameet RV, Ramesh V, Jerajani HR, Rui JF. In:Valia RG, Valia AR, editors. Indian Association of Dermatologists Venereologists and Leprologist (IADVL) textbook and Atlas of dermatology. 2nd ed. Mumbai. Bhalani publishing house. 2015.p.1099-100.

7. Ghodsi SZ, Chams-Davatchi C, Daneshpazhooh M, Valikhani M, Esmaili N. Quality of life and psychological status of patients with pemphigus vulgaris using Dermatology Life Quality Index and General Health Questionnaires. Journal of Dermatology. 2011;38:1-4.

8. Rahbar Z, Daneshpazhooh M, Mirshams-Shahshahani M, Esmaili N, Heidari K, Aghazadeh N, Hejazi P, Ghajarzadeh M, Chams-Davatchi C. Pemphigus disease activity measurements: pemphigus disease area index, autoimmune bullous skin disorder intensity score, and pemphigus vulgaris activity score. JAMA Dermatol. 2014;150(3):266-72.

9. Sokolovska S, Varigos GA, Scardamaglia L. Outcomes of Pemphigus Treatments at the Royal Melbourne Hospital over 5 Years on Immune Suppressive Therapies used over this Time: A Retrospective Analysis. J Clin Exp Dermatol Res. 2004;5:235.

10. Layegh P, Nahidi Y, Malekzadeh I, Shakeri MT, Quality of life evaluation in patients with pemphigus vulgaris, Iran J Dermatol. 2013;16(3):100-4.

11. Grover S. Scoring system in pemphigus. Indian J Dermatol. 2011;56(2):145-9.

12. Finlay AY, Khan GK. Dermatology Life Quality Index (DLQI): a simple practical measure for routine clinical use. Clin Exp Dermatol. 1994;19:210-6.

13. Schumock GT, Thornton JP. Focusing on the preventability of adverse drug reactions. Hosp Pharm.1992;27(6):538.

14. Brenner S, WohlY. A Survey of Sex Differences in 249 Pemphigus Patients and Possible Explanations. SKINmed: Dermatology for the Clinician. 2007;6(4):163-5.

15. Desai MK, Agrawal BC. Television and Cultural crisis. Concept publishing company. 2009

16. Reis VM, Toledo RP, Lopez A, Diaz LA, Martins JE. UVB induced acantholysis in endemic pemphigus foliaceus (fogo selvagem) and pemphigus vulgaris. J Am Acad Dermatol. 2000;42:571-6.

17. Azizi A, Lawaf S. The Management of Oral Pemphigus Vulgaris with Systemic Corticosteroid and Dapsone. Journal of Dental Research, Dental Clinics, Dental Prospects. 2008;2(1):33-7.

18. Pires CA, Viana VB, Araújo FC, Müller SF, Oliveira MS, Carneiro FR. Evaluationof cases of pemphigus vulgaris and pemphigus foliaceus from a reference service 
Kiran, et al:: Evaluation of Pharmacological Management of Pemphigus Vulgaris and its Impact on Quality of Life.

in Pará state, Brazil. An Bras Dermatol. 2014;89(4):556-61.

19. Lunardon L, Payne AS. Rituximab for autoimmune blistering diseases: recent studies, new insights. Giornale italiano di dermatologia e venereologia : organo ufficiale, Societa italiana di dermatologia e sifilografia. 2012;147(3):269-76.

20. Becker KL. Principles and practice of endocrinology and metabolism, $3^{\text {rd }}$ ed. 2001. Philadelphia: Lippincott Williams and Wilkins.

21. Vianna RN, Ozdal PC, Deschênes J, Burnier MN. Combination of azathioprine and corticosteroids in the treatment of serpiginous choroiditis. Can J Ophthalmol 2006;41(2):183-9.
22. Browning JL. B cells move to centre stage: novel opportunities for autoimmune disease treatment. Nat Rev Drug Discov. 2006;5:564-76.

23. Kanwar AJ, Vinay K. Rituximab in pemphigus. Indian J Dermatol Venereol Leprol 2012;78:671-6.

24. Lihite RJ, Lahkar M, Borah A, Hazarika D, Singh S. A study on drug induced Stevens-Johnson Syndrome (SJS), Toxic Epidermal Necrolysis (TEN) and SJSTEN overlap in a tertiary care hospital of Northeast India. J Young Pharma. 2016;8(2):149-53.

Article History: Submission Date : 01-06-2018 ; Revised Date : 03-07-2018; Acceptance Date : 27-07-2018.

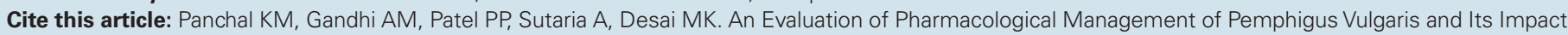
on Quality of Life. J Young Pharm. 2018;10(4):433-8. 